\section{Informed Consent: Is It Really?}

$\mathbf{I}_{\mathrm{B}}^{\mathrm{n}}$ n a rare moment of weakness, I agreed to serve on UCSF's Institutional Review Board. This is a big deal. In addition to meetings every 2 weeks, members need to learn a complex electronic content system (not easy for this Luddite). Members have 3 to 4 assignments involving reams and reams of paper (real or electronic) and each must read the informed consent document in excruciating detail. But I did it because this is important and it was the right thing to do.

However, I must say that if I were a patient, sick and afraid, I would find these informed consent documents to be overwhelming. Although I think we have improved our simplification of language, we have lost our course in making this document easy for patients to navigate.

Let's take a couple of examples. Any patient with cancer on a clinical trial involving a therapeutic intervention will undergo blood tests and imaging. Current rules require that these procedures be detailed in the informed consent document. Sometimes there are more pages on this than on the risks related to the experimental intervention! It doesn't make sense. Because most of our patients have had these procedures as part of their standard of care, could we simply provide a reference compendium in case a patient wants to know more? That alone might eliminate several pages from each document.

Another example is the risk associated with checkpoint inhibitors, such as CTLA-4 inhibitors or PD-1 or PD-L1 inhibitors. The last consent document I looked at included 4 pages of painful details for every possible organ system that could be affected by an autoimmune reaction. Why not just make it simple? We could include something like: "This class of drugs can turn your own immune system against virtually any tissue in your body. Fortunately, this is uncommon and reversible, but the most frequent tissues affected are listed in the following table." Wouldn't that be more straightforward?

Other sticky issues are related to biopsies obtained for research purposes, the risks of genetic analysis on tissue, and the ownership and custody of tissue. But those topics need to be saved for another day.

Right now, I am focused on a template for a clear and understandable informed consent document that does not require an advanced degree to understand. I think that we can personalize these documents according to the patient experience. For instance, a first-line clinical trial might need more detail on procedures than a second-line trial. For drugs that are already FDA-approved for another indication, do we need to detail every possible adverse event? Couldn't we include a statement such as: "DRUG X is already FDA-approved and in wide use for another form of cancer. The most common side effects are listed in the following table."

Finally, I think we need to remember that patients rely more on their trust in us than in an informed consent document. Let's honor that and make this process simpler for everyone!

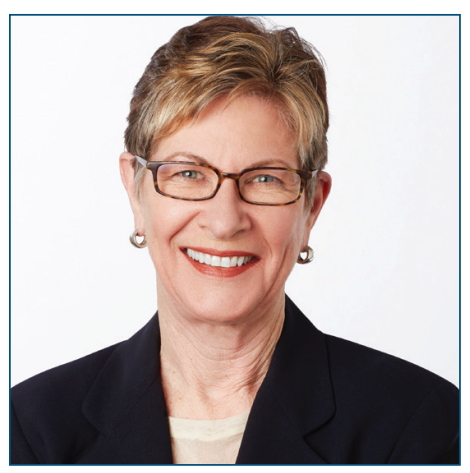

MARGARET TEMPERO, MD

Margaret Tempero, MD, is a Professor of Medicine and Director of the UCSF Pancreas Center and editor-in-chief of JNCCN. Her research career has focused on pancreatic ductal adenocarcinoma, especially in the area of investigational therapeutics. Dr. Tempero has served on the ASCO Board of Directors and as ASCO President. She currently serves on the ASCO Conquer Cancer Foundation Board. She codirected the AACR/ASCO Methods in Clinical Cancer Research and taught this course and similar courses in Europe and Australia. She was founding Chair of the $\mathrm{NCl}$ Clinical Oncology Study Section and served as a member and Chair of the $\mathrm{NCl}$ Board of Scientific Counselors Subcommittee A. She is a member of the Scientific Steering Committee and Chair of the Clinical and Translational Study Section for the Cancer Prevention \& Research Institute of Texas. She is or has been on the Scientific Advisory Boards of the Lustgarten Foundation, the Pancreatic Cancer Action Network, the V Foundation, The Alberta Canada Cancer Board, and the EORTC. She served as a member of the Oncology Drug Advisory Committee for the FDA. She has served as Deputy Director and Interim Director for the UNMC Eppley Cancer Center. She is Chief Emeritus of the Division of Medical Oncology at UCSF. She served as the founding Deputy Director and was later Director of Research Programs at the UCSF Helen Diller Family Comprehensive Cancer Center.

doi: 10.6004/jnccn.2021.0029

The ideas and viewpoints expressed in this editorial are those of the author and do not necessarily represent any policy, position, or program of NCCN. 